\title{
Photoluminescence studies of impurity transitions in AIGaN alloys
}

\author{
N. Nepal, M. L. Nakarmi, J. Y. Lin, and H. X. Jiang ${ }^{\text {a) }}$ \\ Department of Physics, Kansas State University, Manhattan, Kansas 66506-2601
}

(Received 11 April 2006; accepted 29 June 2006; published online 29 August 2006)

\begin{abstract}
Deep ultraviolet photoluminescence (PL) spectroscopy has been employed to investigate impurity transitions in $\mathrm{Si}$ doped Al-rich $\mathrm{AlGaN}$ alloys. In addition to the previously reported donor compensating centers-isolated cation vacancy with three negative charges $\left(V_{\text {III }}\right)^{3-}$ and cation vacancy complex with two-negative charges $\left(V_{\mathrm{III}} \text { complex }\right)^{2-}$ - a group of impurity transitions with higher emission energies has been observed in AlGaN alloys grown under different conditions, which has been assigned to the recombination between shallow donors and cation vacancy complexes with one-negative charge $\left(V_{\mathrm{III}} \text { complex }\right)^{-1}$. Similar to $\left(V_{\mathrm{III}}\right)^{3-}$ and $\left(V_{\mathrm{III}} \operatorname{complex}\right)^{2-}$, the energy levels of $\left(V_{\text {III }} \text { complex }\right)^{1-}$ deep acceptors in $\mathrm{Al}_{x} \mathrm{Ga}_{1-x} \mathrm{~N}(0 \leqslant x \leqslant 1)$ alloys are pinned to a common energy level in vacuum. A strong correlation between the resistivity and PL emission intensities of the impurity transitions associated with cation vacancies (and complexes) was found. (C) 2006 American Institute of Physics. [DOI: 10.1063/1.2337856]
\end{abstract}

AlGaN alloys are recognized as promising materials for applications in optoelectronic devices in deep ultraviolet (UV) spectral range. Highly conductive ( $p$ - and $n$-type) AlGaN alloys are essential for device applications. Although $n$-type AlN by Si doping with a Si energy level ranging from 86 to $250 \mathrm{meV}$ has been reported, ${ }^{1-4}$ further improvements in the material quality and conductivity are still needed for many device applications. One of the major difficulties in obtaining highly conductive $n$-type Al-rich AlGaN alloys is the effect of compensation of electrons by cation vacancies $\left(V_{\text {III }}\right)^{3-}$ and their complexes. It was recognized that suppressing such intrinsic defects could significantly improve the conductivity and material quality of Al-rich AlGaN alloys. ${ }^{1-9}$

Calculations have indicated that the cation vacancy and its complex in undoped and Si-doped AlGaN alloys (particularly in Al-rich alloys) have small formation energies and are easily formed during the crystal growth. ${ }^{5-8}$ The capacitance deep level transient spectroscopy studies revealed at least three dominant deep levels with the same origin in low $\mathrm{Al}$ content $n$-type AlGaN alloys. ${ }^{10}$ We have reported two groups of deep impurity transitions in $\mathrm{Al}_{x} \mathrm{Ga}_{1-x} \mathrm{~N}$ alloys, which were assigned to the recombination between shallow donors and two different deep acceptors, ${ }^{9}$ one of which was identified as an isolated cation vacancy with three-negative charges $\left(V_{\text {cation }}\right)^{3-}$ and the other $V_{\text {cation }}$ complex with two-negative charges $\left(V_{\text {cation }} \text { complex }\right)^{2-}$. The energy levels of these deep acceptors in $\mathrm{AlGaN}$ alloys are pinned to common energy levels in vacuum. ${ }^{9}$ By minimizing the densities of these defects, we have been able to achieve a room temperature $n$-type resistivity of about $40 \Omega \mathrm{cm}$ with a free electron concentration of about $1 \times 10^{17} \mathrm{~cm}^{-3}$ in Si-doped AlN epilayers grown on sapphire substrates. ${ }^{2}$

In this letter, we report on deep UV photoluminescence (PL) studies of impurity transitions related to cation vacancies in $\mathrm{Al}_{x} \mathrm{Ga}_{1-x} \mathrm{~N}$ alloys grown on sapphire substrates by metal organic chemical vapor deposition (MOCVD). Undoped and Si-doped $\mathrm{Al}_{x} \mathrm{Ga}_{1-x} \mathrm{~N}$ alloys of about $1 \mu \mathrm{m}$ thick were grown by MOCVD on AlN/sapphire templates. The Al contents of $\mathrm{Al}_{x} \mathrm{Ga}_{1-x} \mathrm{~N}(0 \leqslant x \leqslant 1)$ alloys were determined by energy dispersive $\mathrm{x}$-ray and x-ray diffraction (XRD) mea-

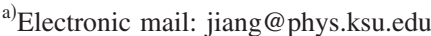

surements. The full width at half maximum of the XRD rocking curve of the (0002) reflection peaks was between 50 and 300 arc sec. Atomic force microscope and scanning electron microscopy were employed to study the surface morphology of these AlGaN alloys, which revealed crack-free smooth surfaces with a roughness of about $1 \mathrm{~nm}$ across a 2 $\times 2 \mu \mathrm{m}^{2}$ scanning area. Deep UV PL spectroscopy was employed to investigate the emission properties of $\mathrm{Al}_{x} \mathrm{Ga}_{1-x} \mathrm{~N}$ epilayers. The PL system consists of a frequency quadrupled 100 fs Ti:sapphire laser, with an average power of $3 \mathrm{~mW}$ with excitation photon energy set at $6.28 \mathrm{eV}$ (repetition rate of $76 \mathrm{MHz})$, and a monochromator $(1.3 \mathrm{~m}){ }^{11}$

Room temperature $(300 \mathrm{~K})$ PL spectra for a set of $\mathrm{Al}_{x} \mathrm{Ga}_{1-x} \mathrm{~N}$ alloys covering the entire alloy range are shown in Fig. 1. The band edge transition peak energy blueshifts from $3.42 \mathrm{eV}$ for $x=0$ to $5.96 \mathrm{eV}$ for $x=1$ in $\mathrm{Al}_{x} \mathrm{Ga}_{1-x} \mathrm{~N}$ alloys. In addition to the band edge transition, each spectrum also exhibits deep impurity transitions. The impurity emission peak at around $2.15 \mathrm{eV}$ (yellow line or YL) in GaN has been extensively studied. It was previously attributed to the transition from a shallow donor to a deep acceptor. ${ }^{5,6,12-15}$ It was suggested that the deep acceptor involved in YL may be linked to $V_{\mathrm{Ga}}-\mathrm{O}_{\mathrm{N}}$ and $V_{\mathrm{Ga}}-2 \mathrm{O}_{\mathrm{N}}$ based on a local-densityfunctional calculation. ${ }^{16}$ Since $\mathrm{O}_{\mathrm{N}}$ sits as a next neighbor of $V_{\mathrm{Ga}}$ to reduce the Coulomb energy, $V_{\mathrm{Ga}}$ forms defect complex with it. ${ }^{5,6}$ More recent studies have suggested that the deep acceptor involved in the YL is related to $V_{\mathrm{Ga}}$ complexes with two-negative charges $\left(V_{\mathrm{III}} \text { complex }\right)^{2-}$ such as $\left(V_{\mathrm{Ga}}-\mathrm{O}_{\mathrm{N}}\right)^{2-}$ or $\left(V_{\mathrm{Ga}}-\mathrm{Si}_{\mathrm{Ga}}\right)^{2-}{ }^{7-9}$ The PL emission peak at $3.4 \mathrm{eV}$ (violet line or VL) in AIN was first observed by Youngman and Harris. ${ }^{17}$ Our recent studies have suggested that the VL in AIN is due to the transition from shallow donors to isolated $\mathrm{Al}$ vacancies with three-negative charges $\left(V_{\mathrm{Al}}\right)^{3-}$. By examining the PL spectra shown in Fig. 1, besides $\left(V_{\mathrm{III}}\right)^{3-}$ and $\left(V_{\mathrm{III}} \text { complex }\right)^{2-}$, a group of impurity transitions (indicated with dark arrows) with emission energies above those of $\left(V_{\mathrm{III}}\right)^{3-}$ and $\left(V_{\mathrm{III}} \text { complex }\right)^{2-}$ related transitions has been observed. The spectral peak position of this group of impurity transitions blueshifts from $2.86 \mathrm{eV}$ in $\mathrm{GaN}$ to $4.71 \mathrm{eV}$ in AlN. The blue band $(2.8 \mathrm{eV})$ has been observed in $\mathrm{Si}$ and undoped GaN by PL, cathodoluminescence, 


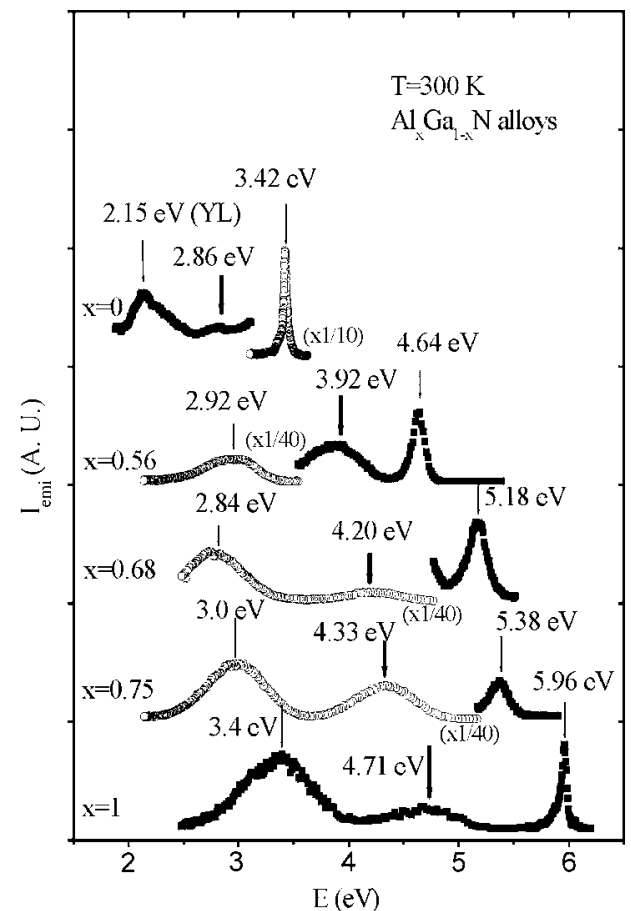

FIG. 1. Room temperature PL spectra of $\mathrm{Al}_{x} \mathrm{Ga}_{1-x} \mathrm{~N}$ alloys with $x$ between 0 and 1 , showing the band edge and impurity transitions. A group of impurity transitions has been identified and their peak positions are marked with bold arrows.

and photoconductivity measurements ${ }^{18-20}$ and was attributed to a $V_{\mathrm{Ga}}-\mathrm{O}_{\mathrm{N}}$ complex related transition. ${ }^{18}$

In Fig. 2, we plot the room temperature PL spectral peak position $\left(E_{\mathrm{imp}}\right)$ of the newly observed impurity transition in $\mathrm{Al}_{x} \mathrm{Ga}_{1-x} \mathrm{~N}$ alloys as a function of $x$ (closed squares) together with those of $\left(V_{\text {III }}\right)^{3-}$ and $\left(V_{\text {III }} \text { complex }\right)^{2-}$ related transitions (open circles and open squares, respectively). ${ }^{9}$ The energy position of this impurity transition shows a continuous increase with $x$ and follows the same trend as those of $\left(V_{\mathrm{III}}\right)^{3-}$

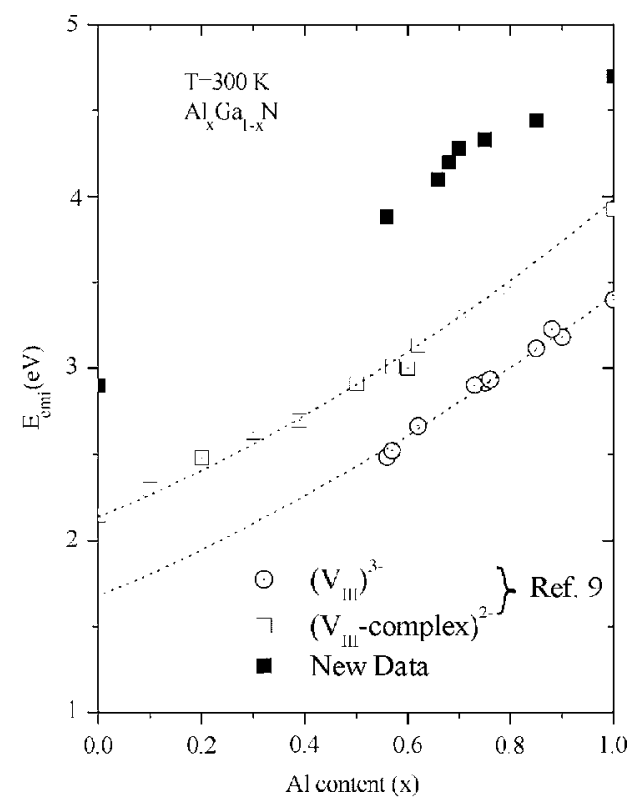

FIG. 2. PL peak position $\left(E_{\text {imp }}\right)$ of the presently observed impurity transition obtained from Fig. 1 (closed squares) and those of $\left(V_{\text {III }}\right)^{3-}$ and $\left(V_{\text {III }} \text { complex }\right)^{2-}$ related transitions from Ref. 9 (open circle and squares) in $\mathrm{Al}_{x} \mathrm{Ga}_{1-x} \mathrm{~N}$ as functions of $\mathrm{Al}$ content $(x)$. Dotted lines are guides for the eyes.

Downloaded 12 Jul 2010 to 129.118 .86 .45 . Redistribution subject

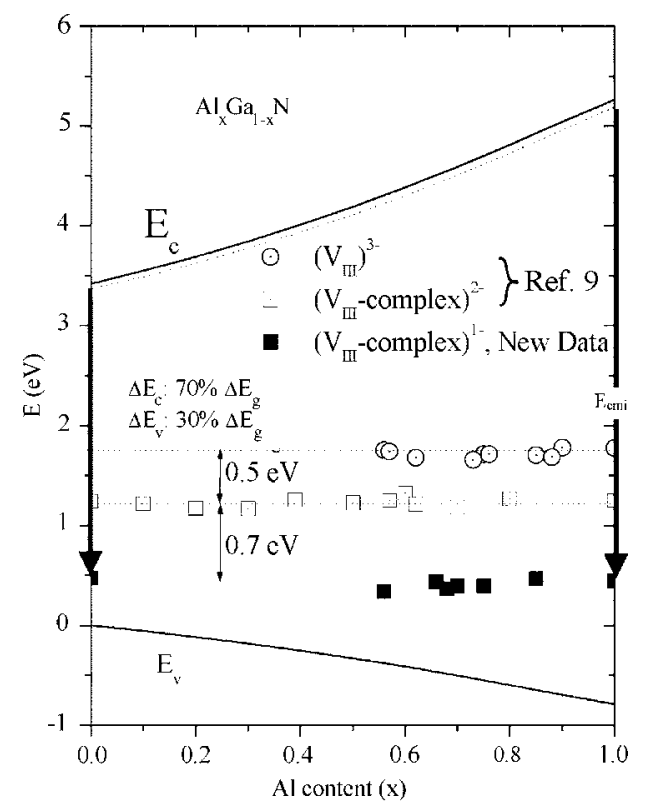

FIG. 3. Deep acceptor energy levels $\left(E_{A}\right)$ associated with $\left(V_{\text {III }} \text { complex }\right)^{1-}$ (closed squares), $\left(V_{\mathrm{III}} \text { complex }\right)^{2-}$ (open squares), and $\left(V_{\mathrm{III}} \text { complex }\right)^{3-}$ (open circles) obtained from Figs. 1 and 2 and Ref. 9 plotted together with $E_{c}, E_{v}$, and $E_{D}^{0}$ as functions of $\mathrm{Al}$ content $(x)$.

and $\left(V_{\mathrm{III}} \text { complex }\right)^{2-}$ related transitions, indicating that they are of the similar nature- the presently observed impurity transition shown in Fig. 1 is of donor-acceptor pair (DAP)type involving shallow donors and deep acceptors. Our timeresolved PL measurements also revealed long decay lifetimes (longer than $0.1 \mu \mathrm{s}$ ) for this group of impurity transitions, which supports our assignment.

To further identify the origin of this deep acceptor, we plot in Fig. 3 its energy level $\left(E_{A}\right)$ together with the conduction $\left(E_{c}\right)$ and valence $\left(E_{v}\right)$ band edges as functions of $\mathrm{Al}$ content $(x)$. In obtaining Fig. 3, we used the commonly known compositional dependence of the band gap of $\mathrm{Al}_{x} \mathrm{Ga}_{1-x} \mathrm{~N}, \quad E_{g}(x)=(1-x) E_{g}(\mathrm{GaN})+x E_{g}(\mathrm{AlN})-b x(1-x)$, where the bowing parameter $(b)$ and the room temperature energy band gaps of GaN and AlN were taken as 1, 3.44, and $6.05 \mathrm{eV}$, respectively. The conduction $\left(E_{c}\right)$ and valence $\left(E_{v}\right)$ band offset parameters have been assumed to be $70 \%$ and $30 \%$ for $\mathrm{Al}_{x} \mathrm{Ga}_{1-x} \mathrm{~N}(0 \leqslant x \leqslant 1)$ alloys, respectively. The valence band maximum of $\mathrm{GaN}$ is chosen as $E=0$. Assuming that the ionization energies of the shallow donors $\left(E_{D}^{0}\right)$ increase linearly from 25 to $86 \mathrm{meV}$ with varying $x$ from 0 to 1 in $\mathrm{Al}_{x} \mathrm{Ga}_{1-x} \mathrm{~N}$ alloys, ${ }^{1,2}$ the acceptor level $\left(E_{A}\right)$ deduced from Figs. 1 and 2 neglecting the Coulomb interaction between the ionized donors and acceptors is then given by

$$
E_{A}=E_{g}(x)-E_{\mathrm{emi}}-E_{D}+E_{v},
$$

where $E_{g}(x)$ is the band gap of $\mathrm{Al}_{x} \mathrm{Ga}_{1-x} \mathrm{~N}$ alloys, $E_{v}=-0.3 \Delta E_{g}(x), \mathrm{E}_{c}=\mathrm{E}_{g}(\mathrm{GaN})+0.7 \Delta E_{g}(x)$, and $E_{D}$ is the shallow donor energy level. $E_{A}$ is plotted in Fig. 3 (closed squares) together with $E_{c}$ and $E_{v}$ as functions of $x$. The result clearly shows that the newly observed deep acceptor has a binding energy of $1.25 \mathrm{eV}(0.55 \mathrm{eV})$ in AlN $(\mathrm{GaN})$. The striking feature is that, similar to $\left(V_{\mathrm{III}}\right)^{3-}$ and $\left(V_{\mathrm{III}} \text { complex }\right)^{2-}$ deep acceptor levels in $\mathrm{Al}_{x} \mathrm{Ga}_{1-x} \mathrm{~N}$ alloys, the deduced energy level of the presently observed deep acceptor as a function of $x$ is also a horizontal line in the wholerange of $x$. This clearly indicates that the energy levels 


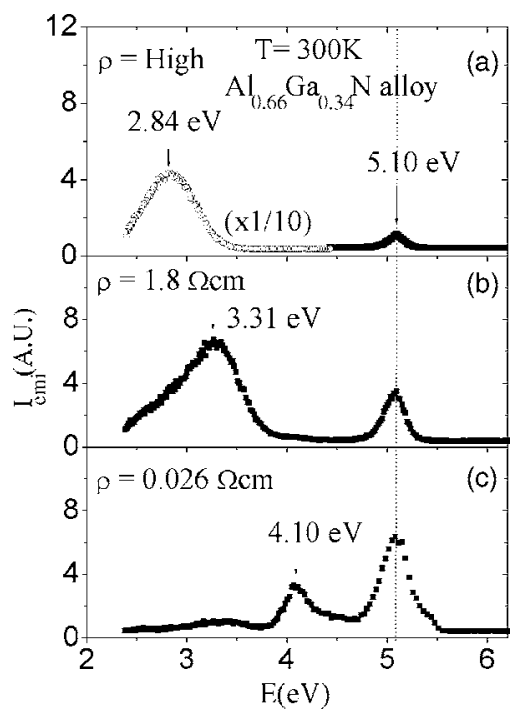

FIG. 4. Room temperature PL spectra of $\mathrm{Al}_{0.66} \mathrm{Ga}_{0.34} \mathrm{~N}$ alloys with different resistivities.

of these deep acceptors in $\mathrm{Al}_{x} \mathrm{Ga}_{1-x} \mathrm{~N}$ alloys are also pinned to a common energy level in vacuum with energy separations of 0.7 and $1.2 \mathrm{eV}$ from those of $\left(V_{\mathrm{III}} \text { complex }\right)^{2-}$ and $\left(V_{\mathrm{III}}\right)^{3-}$, respectively.

The formation energies $\left(E_{f}\right)$ of cation vacancies and vacancy complexes have been calculated in GaN and AlN, which shows that $E_{f}$ of $\left(V_{\mathrm{III}}\right)^{3-}$ and $\left(V_{\mathrm{III}} \text { complex }\right)^{2-}$ are lower than that of $\left(V_{\mathrm{III}} \text { complex }\right)^{1-}$ and anion vacancies cannot be formed in Si-doped GaN and AlN. ${ }^{6-8}$ From the energy position relative to those of $\left(V_{\mathrm{III}}\right)^{3-}$ and $\left(V_{\mathrm{III}} \text { complex }\right)^{2-}$, we believe that the deep level acceptor involved in the presently observed impurity transitions is cation vacancy complex with one-negative charge $\left(V_{\mathrm{III}} \text { complex }\right)^{1-}$, such as $\left(V_{\mathrm{Ga}}-2 \mathrm{O}_{\mathrm{N}}\right)^{1-}$. The possibility of isolated $\left(V_{\mathrm{III}}\right)^{1-}$ as the origin of the presently observed deep acceptor in $\mathrm{Al}_{x} \mathrm{Ga}_{1-x} \mathrm{~N}$ alloys can be excluded due to its much higher formation energy than $\left(V_{\text {III }} \text { complex }\right)^{1-}$. The binding energies of the $\left(V_{\mathrm{III}}-2 \mathrm{O}_{\mathrm{N}}\right)^{1-}$ deep level acceptors in $\mathrm{Al}_{x} \mathrm{Ga}_{1-x} \mathrm{~N}$ alloys increase almost linearly from about 0.55 to $1.25 \mathrm{eV}$ with varying $x$ from 0 to 1 . The calculated binding energy of $\left(V_{\mathrm{Al}}-2 \mathrm{O}_{\mathrm{N}}\right)^{1-}$ ranges from 1.0 to $1.12 \mathrm{eV}$ in AlN. ${ }^{6,8}$ The calculated differences in binding energies between $\left(V_{\mathrm{III}}\right)^{3-}$ and $\left(V_{\mathrm{Al}}-2 \mathrm{O}_{\mathrm{N}}\right)^{2-}$ and between $\left(V_{\mathrm{Al}}-2 \mathrm{O}_{\mathrm{N}}\right)^{2-}$ and $\left(V_{\mathrm{Al}}-2 \mathrm{O}_{\mathrm{N}}\right)^{1-}$ in AlN, respectively, are about 0.5 and $0.7 \mathrm{eV},{ }^{6,8}$ which agree perfectly with our experimentally measured values shown in Fig. 3 (0.5 and $0.7 \mathrm{eV})$.

Since $\left(V_{\mathrm{III}}-2 \mathrm{O}_{\mathrm{N}}\right)^{1-}$ captures only one electron, their presence will not detriment the conductivity as severely as the presence of $\left(V_{\mathrm{III}}\right)^{3-}$ and $\left(V_{\mathrm{Al}}-2 \mathrm{O}_{\mathrm{N}}\right)^{1-}$ defects, which is consistent with our experimental results presented in Fig. 4. Figure 4 illustrates the evolution of room temperature $(300 \mathrm{~K})$ PL spectra and resistivity of $\mathrm{Al}_{x} \mathrm{Ga}_{1-x} \mathrm{~N}$ alloys $(x \sim 0.66)$ grown under various conditions. All samples exhibit a band edge transition at $5.10 \mathrm{eV}$ and the band edge emission intensity increases with decreasing resistivity. As shown in Fig. 4(a), for an early grown Si-doped $\mathrm{Al}_{0.66} \mathrm{Ga}_{0.34} \mathrm{~N}$ alloy with high resistivity (beyond our instrument limitation), the dominant impurity peak at $2.84 \mathrm{eV}$ is related to the isolated cation vacancy, $\left(V_{\text {III }}\right)^{3-}$. The triply charged cation vacancy captures three electrons and thus their presence significantly increases the resistivity. As illus- trated in Fig. 4(b), suppression of $\left(V_{\mathrm{III}}\right)^{3-}$ related transition results in a reduction in resistivity to $1.8 \Omega \mathrm{cm}$ and simultaneously an emission peak at 3.31 associated with the presence of $\left(V_{\text {III }} \text { complex }\right)^{2-}{ }^{-9}$ As illustrated in Fig. 4(c), once $\left(V_{\mathrm{III}}\right)^{3-}$ and $\left(V_{\mathrm{III}} \text { complex }\right)^{2-}$ related transitions were suppressed by varying the growth conditions, we have significantly reduced the sample resistivity to $0.026 \Omega \mathrm{cm}$. However, an impurity transition involving $\left(V_{\mathrm{III}} \text { complex }\right)^{1-}$ at $4.10 \mathrm{eV}$ is evident. We believe that the conductivities of Alrich $\mathrm{AlGaN}$ alloys and pure AlN will continue to improve by further reducing the densities of the intrinsic defects-cation vacancies (and complexes) with triple-, double-, and singlenegative charges.

In summary, we have investigated impurity transitions involving cation vacancies and complexes in $\mathrm{Al}_{x} \mathrm{Ga}_{1-x} \mathrm{~N}$ alloys between $x=0$ and 1 . A group of impurity transitions of DAP type with higher emission energies than those of the previously identified $\left(V_{\mathrm{III}}\right)^{3-}$ and $\left(V_{\mathrm{III}} \text { complex }\right)^{2-}$ related transitions was observed. The deep level acceptors involved in these transitions have been identified as $\left(V_{\mathrm{III}} \text { complex }\right)^{1-}$. The energy levels of these deep acceptors in $\mathrm{Al}_{x} \mathrm{Ga}_{1-x} \mathrm{~N}$ alloys increase almost linearly with $x$ from $0.55 \mathrm{eV}$ in $\mathrm{GaN}$ to $1.25 \mathrm{eV}$ in AlN and are pinned to a common energy level in vacuum. Experimentally measured energy difference between the $\left(V_{\mathrm{III}} \text { complex }\right)^{2-}$ and $\left(V_{\mathrm{III}} \text { complex }\right)^{1-}$ deep level acceptors in AlGaN alloys $(0.7 \mathrm{eV})$ agrees with the calculated value $(0.7 \mathrm{eV})$. AlGaN alloys predominantly exhibiting the band edge and $\left(V_{\mathrm{III}} \text { complex }\right)^{1-}$ transitions possess improved conductivities over those emit predominantly $\left(V_{\text {III }}\right)^{3-}$ and $\left(V_{\mathrm{III}} \text { complex }\right)^{2-}$ related transitions.

This research is supported by grants from NSF (DMR0504601).

${ }^{1}$ Y. Taniyasu, M. Kasu, and N. Kobayashi, Appl. Phys. Lett. 81, 1255 (2002).

${ }^{2}$ M. L. Nakarmi, K. H. Kim, K. Zhu, J. Y. Lin, and H. X. Jiang, Appl. Phys. Lett. 85, 3769 (2004)

${ }^{3}$ Y. Taniyasu, M. Kasu, and T. Makimoto, Appl. Phys. Lett. 85, 4672 (2004).

${ }^{4}$ T. Ive, O. Brandt, H. Kostial, K. J. Friedland, L. Daweritz, and K. H. Ploog, Appl. Phys. Lett. 86, 024106 (2005).

${ }^{5}$ J. Neugebauer and C. G. Van de Walle, Appl. Phys. Lett. 69, 503 (1996).

${ }^{6}$ T. Mattila and R. M. Nieminen, Phys. Rev. B 55, 9571 (1997).

${ }^{7}$ C. Stampfl and C. G. Van de Walle, Phys. Rev. B 65, 155212 (2002).

${ }^{8}$ I. Gorczyca, N. E. Christensen, and A. Svane, Phys. Rev. B 66, 075210 (2002).

${ }^{9}$ K. B. Nam, M. L. Nakarmi, J. Y. Lin, and H. X. Jiang, Appl. Phys. Lett. 86, 222108 (2005).

${ }^{10}$ J. Osaka, Y. Ohno, S. Kishimoto, K. Maezawa, and T. Mizutani, Appl. Phys. Lett. 87, 222112 (2005).

${ }^{11}$ http://www.phys.ksu.edu/area/GaNgroup

${ }^{12}$ T. Ogino and M. Aoki, Jpn. J. Appl. Phys. 19, 2395 (1980).

${ }^{13}$ S. J. Rhee, S. Kim, E. E. Reuter, and S. G. Bishop, Appl. Phys. Lett. 73, 2636 (1998).

${ }^{14}$ P. Perlin, T. Suski, H. Teisseyre, M. Leszczynski, I. Grzegory, J. Jun, S. Porowski, P. Bogustawski, J. Bernholc, J. C. Chervin, A. Polian, and T. D. Moustakas, Phys. Rev. Lett. 75, 296 (1995).

${ }^{15}$ B. J. Skrome, J. Jayapalan, R. P. Vaudo, and V. M. Phanse, Appl. Phys. Lett. 74, 2358 (1999).

${ }^{16}$ J. Elsner, R. Jones, M. I. Heggie, P. K. Sitch, M. Haugk, Th. Frauenheim, S. Oberg, and P. R. Briddon, Phys. Rev. B 58, 12571 (1998).

${ }^{17}$ R. A. Youngman and J. H. Harris, J. Am. Ceram. Soc. 73, 3238 (1990).

${ }^{18}$ H. C. Yang, T. Y. Lin, and Y. F. Chen, Phys. Rev. B 62, 12593 (2000).

${ }^{19}$ A. V. Fomin, A. E. Nikolaev, I. P. Nikitina, A. S. Zubrilov, M. G. Mynbaeva, N. I. Kuznetsov, A. P. Kovarsky, B. Ja. Ber, and D. V. Tsvetkov, Phys. Status Solidi A 188, 433 (2001).

${ }^{20}$ I. Shai, C. E. M. de Oliviera, Y. Shapira, and J. Salzman, Phys. Rev. B 64, 205313 (2001).

AIP license or copyright; see http://apl.aip.org/apl/copyright.jsp 